\title{
The potential roles of $p 53$ tumor suppressor in nucleotide excision repair (NER) and base excision repair (BER)
}

\author{
Young Rok Seo ${ }^{1,2}$ and Hwa Jin Jung ${ }^{1}$ \\ 'Department of Pharmacology \\ Institute for Basic Medical Science (IBMS) \\ College of Medicine, Kyung Hee University \\ Dongdaemun-gu, Seoul 130-701, South Korea \\ ${ }^{2}$ Corresponding author: Tel, 82-2-961-0674; \\ Fax, 82-2-968-0560; E-mail, dream21@khu.ac.kr
}

\section{Accepted 17 November 2004}

Abbreviations: AP endonuclease, apurinic/apyrimidinic endonuclease; BER, base excision repair; MMS, methyl methanesulfonate; NER, nucleotide excision repair; PCNA, proliferating cell nuclear antigen; $\beta$-pol, DNA polymerase beta

\begin{abstract}
The p53 tumor suppressor has long been envisaged to preserve genetic stability by the induction of cell cycle checkpoints and apoptosis. More recently, p53 has been implicated to play roles in DNA repair responses to genotoxic stresses. UV-damage and the damage caused by certain chemotherapeutics including cisplatin and nitrogen mustards are known to be repaired by the nucleotide excision repair (NER) pathway which is reportedly regulated by $p 53$ and its downstream genes. There are evidences to suggest that the base excision repair (BER) induced by the base-damaging agent methyl methanesulfonate (MMS) is partially deficient in cells lacking functional $p 53$. This result suggests that the activity of BER might be also dependent on the p53 status. In this review, we discuss the possibilities that $p 53$ regulates BER as well as NER; these are one of the most significant potentials of p53 tumor suppressor for repairing the vast majority of DNA damages that is incurred from various environmental stresses.
\end{abstract}

Keywords: DNA damage; DNA polymerase beta; DNA repair; DNA repair enzymes; nucleotide excision repair (NER); protein p53

\section{Introduction}

Genomic guardian, p53 tumor suppressor

p53 has been identified as a tumor suppressor protein to protect cells from DNA damage. Over the past 10 years, p53 has been known to be activated by a wide range of agents that induce genotoxic damages, such as UV irradiation, chemical carcinogens, and oxidative stress. Moreover, p53 activation was also induced by non-genotoxic damage including hypoxia and oncogene activation (Pluquet and Hainaut, 2001). Generally, the investigation of p53 activation and its regulation has been focused on post-translational modification (Ryan et al., 2001) such as phosphorylation (Meek, 1999), acetylation (Gu and Roeder, 1997) and sumoylation (Gostissa et al., 1999; Rodriguez et al., 1999). In addition, the regulation of p53 protein stability was reported to be the essentials of $p 53$ function (Appella and Anderson, 2001; Brooks and Gu, 2003). The other side, p53 activation by oxidative/reductive (redox) modulation has been reported (Ueno et al., 1999). The activation of p53 might be mediated by the redox-sensitive interactions between redox factor-1 (Ref-1) and thioredoxin (TRX) (Gaiddon et al., 1999; Seo et al., 2002c) (Figure 1).

Activated p53 is involved in maintaining stability of the genome through the induction of various cellular responses. In some cell types, p53 activation triggers apoptosis (Choi et al., 2000; Lee et al., 2000), while in other cell types, p53 protein displays a protective function, attributable not only to the activation of cell cycle checkpoints, but also to the enhancement of DNA repair (Ko and Prives 1996; Giaccia and Kastan, 1998; Prives and Hall, 1999) (Figure 1). P53 has a well known role as a sequence- specific transcription factor that is able to mediate its downstream effector genes. Indeed, Tokino and his college have suggested that there might be more than 200 p53-regulated genes in the human genome and already there have been 57 tagged sequences, corresponding to p53 binding sites isolated from human genomic library (Tonkino et al., 1994). The p21 $1^{\text {cip } 1 / \text { waf1 }}$ gene product, for instance, is one of the major mediators of p53mediated $\mathrm{G} 1$ cell cycle arrest by inhibiting the activity of cyclin-CDK2 or the CDK4 complexes. On the other hand, Bax, as the bcl2-homogous counterpart induces apoptosis with its translocation from the cytosol to the mitochondria. More recently, gadd45a, which has been identified as one of p53-regulated genes and a stress-inducible protein, has been reported to be 


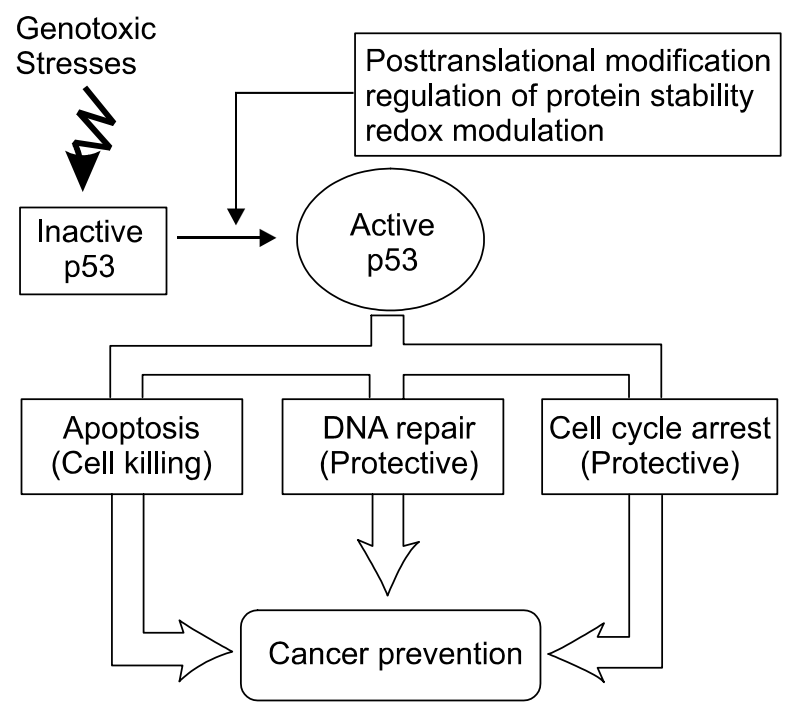

Figure 1. Various roles of p53 tumor suppressor in response to genotoxic stresses. p53 has been shown to be activated via post-translational modification, regulation of protein stability, and redox modulation. Activated p53 plays a role as a transcription factor for stimulating a range of cellular responses. p53 induces apoptosis to kill the damaged cells if the damage in cells is too extensive. On the other hand, p53 enhances DNA repair and cell cycle arrest to protect cells against DNA damages. These p53-mediated cellular responses might provide a cancer preventive effect against various environmental stresses.

involved in DNA repair as well as $G_{2} / M$ arrest, though the detailed mechanisms still need to be discussed (Smith et al., 2000; Jin et al., 2002) (Figure 1).

Despite a body of literature documenting the p53mediated cellular responses for maintaining genomic stability under genotoxic conditions, there is not so much knowledge concerning the DNA repair mechanisms regulated by $p 53$. Thus, this overview primarily focuses on the roles of p53 tumor suppressor in DNA repair, particularly nucleotide excision repair (NER) and base excision repair (BER), in mammalian cells against DNA damages. Our discussion on DNA repair under p53 regulation would be helpful for understanding the novel feature of p53 for mediating a protective response under mutagenic environmental stresses.

\section{Potential roles for $p 53$ in NER and BER}

The DNA repair system is crucial for the genomic maintenance. Alterations in DNA structure, if left unrepaired, cause mutation that enhances the risk of cancer. Genomic instabilities are induced by the usual metabolic processes as well as by exogenous factors such as diet, life style, and environmental stresses such as solar radiation. Indeed, DNA repair is one of the major cellular responses to minimize genetic alterations. Deficiency of DNA repair is now believed to be a significant carcinogenic event. Among the DNA repair pathways, nucleotide excision repair (NER) is the primary process to remove bulky DNA adducts such as UV-induced pyrimidine dimmers and polycyclic aromatic hydrocarbone. This system comprises one of the major DNA repair pathways in cells and it provides a significant barrier against neoplasia, mutagenesis, and cytotoxicity. In contrast, the base excision repair pathway (BER) is believed to maintain genomic integrity by correcting DNA base modifications. Base damages are frequently generated by reactive oxygen species including superoxide, hydro$x y l$ radical, and hydrogen peroxide, and these DNA damages are corrected by BER (Lee et al., 2003). Moreover, base alkylation damages from endogenous alkylating agents (e.g. S-adenosylmethionine) and from monofunctional alkylating agents (e.g., methyl methanesulfonate (MMS) and vinyl chloride) are also repaired by BER. This DNA repair system is also responsible for the repair of abasic sites, which may arise spontaneously as a function of temperature fluctuations or which may arise as intermediates in the DNA repair process.

One similarity between NER and BER is that both processes are carried out by multiprotein complexes composed of approximately 20 proteins (Matsumoto et al., 1999). A second similarity is that incision is required to occur on the damaged DNA strand, with subsequent re-synthesis of the correct sequence information by using the complementary strand as a template. The repair patch size differs, however, in that the BER repair patch is 1-6 bases in length, while NER produces repair patches approximately 30 bases in length (Friedberg et al., 1995). The multiprotein complexes that carry out BER and NER differ for most of the subunits, even though a few proteins such as proliferating cell nuclear antigen (PCNA) and $X P-G$ (the product of the xeroderma pigmentosum complementation group $G$ gene) are found in both $B E R$ and NER repairosome complexes (Matsumoto et al., 1999). Both repairosome complexes contain a DNA polymerase with which to conduct repair synthesis, DNA polymerases $\varepsilon$ and $\delta$ for NER, and DNA polymerase $\beta$ for BER (Stucki et al., 1998).

The DNA excision repair genes that have been suggested to be regulated by $p 53$ are Gadd45a, p48-XPE, and DNA polymerase. Gadd45a has been suggested to play a role in binding to UV-damaged chromatin and it also affects accessibility to the sites of DNA damages (Smith et al., 2000). Gadd45 protein is known to interact with proliferating cell nuclear antigen (PCNA), core histones, and p21. In addition, reduced repair of UV-damaged DNA was observed in gadd45-deficeint cells (Smith et al., 2000). Recent studies using gadd45-null cells have shown the increase of multiple chromosome abnormalities and ra- 


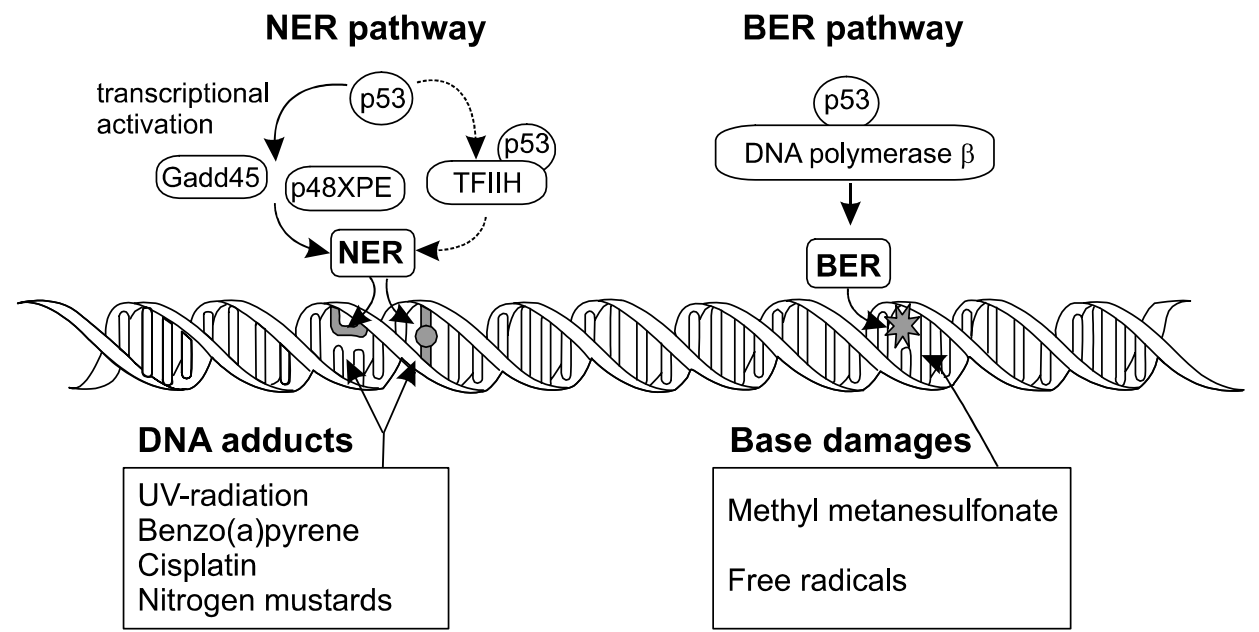

Figure 2. Potential roles for $p 53$ in DNA excision repair. $p 53$ plays a significant roles in NER as a transcriptional factor for the regulation of gadd45 and p48-XpE (Smith et al., 2000), resulting in the enhancement of the repair of carcinogen-induced DNA damages caused by agents such as UV and benzopyrene. p53 also affects the sensitivity to DNA-damaging chemotherapeutic agents including cisplatin and nitrogen mustards (Fan et al., 1995). In addition to NER, p53 regulates the BER response to base-damaging agents. The evidence so far implies that 553 protein might interact with DNA polymerase beta, which is required for BER (Zhou et al., 2001).

diation carcinogenesis, suggesting that gadd45 contributes to maintenance of genomic stability. p48-XPE (xeroderma pigmentosum group $\mathrm{E}$ ), is a component of NER protein complex, and it is involved in the process of binding to UV-damaged DNA as the small subunit of the heterodimeric damage-specific DNA binding protein (DDB) (Hwang et al., 1999). As unique clinical and cellular phenotype among the eight known XP groups, XP-E patients suffer from skin cancers without displaying the typical xerosis. In addition, cell strains from XP-E patients are abnormally sensitive to UV treatment (Itoh et al., 2000). DNA polymerase $\beta$ $(\beta-p o l)$, one of major factors in BER protein complex, participates in filling in the incised repair patch, following incision of the damaged strand 5' of AP site. This $\beta$-pol enzyme also contributes to removing the overhang created by the displaced strand (Wilson and Kunkel, 2000). Indeed, mice lacking the $\beta$-pol gene exhibit a BER-deficient phenotype and mouse embryonic fibroblasts (MEFs) derived from $\beta$-pol-null mice showed sensitivity to a typical DNA base-damaging agent MMS (Wilson and Kunkel, 2000).

In the case of NER, p53 affects DNA repair through the transcriptional activation of downstream effector genes such as gadd45a (Smith et al., 2000) and p48-XPE (Hwang et al., 1999) (Figure 2). The possibility of $p 53-d e p e n d e n t$ DNA repair in vivo has been supported by the observations that p53 increased global genomic repair, but not the transcription-coupled repair (NER; Hwang et al., 1999). A direct role for $p 53$ in NER has been implied, but this has been difficult to demonstrate. Specifically, the addition of recombinant p53 protein in vitro did not enhance NER (Leveillard et al., 1996).

On the contrary, in the case of BER, several reports have suggested the role for the p53 protein itself. The addition of recombinant p53 did stimulate DNA repair in cells (Offer et al., 2001). Specifically, $\beta$-pol repair synthesis in vitro was increased by $p 53$ recombinant protein, suggesting the direct interaction of $p 53$ and $\beta$-pol (Zhou et al., 2001) or the direct roles of $\mathrm{p} 53$ protein in BER pathways. These results support our previous data showing the alteration of $\beta$-pol protein expression in p53-deficient cells (Seo et al., 2002b). Interestingly, p53 has also been shown to interact with APE (Jayaraman et al., 1997). These reports suggest that p53 may play a direct role in $B E R$ through protein-protein interaction among p53 and BER proteins ( $\beta$-pol, APE) (Figure 2).

\section{Implications for carcinogenesis and chemotherapeutics}

The importance of $p 53$ for safeguarding genetic information has long been recognized with the formal proof being in the form of p53-null mice that exhibited genetic instability and enhanced rates of carcinogenesis (Donehower et al., 1992), and this is consistent with the idea of p53 having a 'tumor suppressor' function. In exploring the downstream genes that contribute to this important phenotype, mice lacking p $21^{\text {waf1/cip } 1}$ genes were generated. The mice exhibited the degradation of cell cycles, as predicted with the loss of cyclin-dependent kinase inhibitor, but the 
instability of genome was not observed (Deng et al., 1995). There has also been tremendous attention given to p53-mediated apoptosis, an important cellular response that is most predominate in lymphoid cells (Fan et al., 1994). The p53-regulated bax gene is an important mediator of apoptosis, but mice lacking bax gene did not exhibit genomic instability (Knudson et al., 1995). One could conclude that more than one p53-regulated gene contributes to a condition of genomic instability and a cancer-prone phenotype, which would not be recapitulated by single gene knockouts. Indeed, our group suggests the possibility that DNA repair deficiencies such as the BER defects would be found to contribute, to a large degree to the enhanced carcinogenesis associated with p53 loss (Hollander et al., 2001; Seo et al., 2002b).

It was predicted that many of cancer chemotherapeutic drugs are DNA-damaging agents that involve a p53-regulated component for the repairing of their respective damages (Hawkins et al., 1996). Fan et al showed that p53-defective breast cancer cells were preferentially sensitive to nitrogen mustards (Fan et al., 1995). More recently, we have obtained evidence of enhanced sensitivity to oxaliplatin and thio-TEPA $(\mathrm{N}, \mathrm{N}$ ', N"-triethylene phosphoramide; Seo et al., 2002a). The recent findings showing the sensitivity of p53 defective cells to the base-damaging agent MMS (Lackinger and Kaina, 2001; Seo et al., 2002b), suggest that certain p53-deficient cancers may be preferentially sensitive to chemotherapeutic base-damaging agents e.g. cyclophosphamide, that is repaired by BER. However, as has been noted by other authors, there have been surprisingly few studies on the role of p53 in response to DNA-damaging chemotherapeutic agents for the treatment of epithelial cancers that are not intrinsically prone to undergo apoptosis (Brown and Wouters, 1999).

\section{Concluding remarks}

In this review, we suggested an emerging role of p53 for DNA repair as a protective response to genotoxic stresses. Particularly, we focused on base excision repair (BER) as well as nucleotide excision repair (NER) for eliminating mutagenic and carcinogenic risks. Indeed, the elimination of damaged cells by apoptosis is probably the important mechanism of cancer prevention and chemotherapies. However, it is not feasible that apoptosis induction by itself is able to remove all the mutagenic risk incurred under genotoxic stresses, and thus the capacity of DNA repair might be another key determinant of the predisposition for cancer. Therefore, further studies of the DNA repair pathways and their regulation by $p 53$ are clearly warranted, and the future results are likely to yield a wealth of biologically and therapeuticallyrelevant findings.

\section{Acknowledgement}

We thank Dr. Martin Smith for his insightful comments on the manuscript. We also thank Byung J. Kim and Jee $\mathrm{Na}$ Hwang for helping with the illustration work. This work was partially supported by a grant of the Korea Health 21 R\&D Project (03-PJ1-PG3-208000011), Ministry of Health and Welfare, by the grant of the Eco-technopia 21 project (2004-09001-0025-2) of Ministry of Environment, and by a grant No. R132002-020-01005-0 from the Korea Science and Engineering Foundation, Republic of Korea.

\section{References}

Appella E, Anderson CW. Post-translational modifications and activation of $\mathrm{p} 53$ by genotoxic stresses. Eur J Biochem 2001;268:2764-72

Brooks CL, Gu W. Ubiquitination, phosphorylation and acetylation: the molecular basis for p53 regulation. Curr Opin Cell Biol 2003;15:164-71

Brown JM, Wouters BG. Apoptosis, p53, and tumor cell sensitivity to anticancer agents. Cancer Res 1999;59:1319-9

Choi JH, Anh KS, Kim J, Hong YS. Enhanced induction of Bax gene expression in $\mathrm{H} 460$ and $\mathrm{H} 1299$ cells with the combined treatment of cisplatin and adenovirus mediated wt-p53 gene transfer. Exp Mol Med 2000;32:23-8

Deng C, Zhang P, Harper JW, Elledge SJ, Leder P. Mice lacking p21cip1/waf1 undergo normal development but are defective in G1 checkpoint control. Cell 1995;82:675-84

Donehower LA, Harvey M, Slagle BL, McArthur MJ, Montgomery CA Jr, Butel JS, Bradley A. Mice deficient for p53 are developmentally normal but susceptible to spontaneous tumors. Nature 1992; 56:215-21

Fan S, el-Deiry WS, Bae L, Freeman J, Jondle D, Bhatia K, Fornace AJ Jr, Magrath I, Kohn KW, O'Connor PM. p53 gene mutations are associated with decreased sensitivity of human lymphoma cells to DNA damaging agents. Cancer Res 1994;54:5824-30

Fan S, Smith ML, River DJ, Duba D, Zhan Q, Kohn KW, Fornance AJ Jr, O' Connor PM. Disruption of p53 function sensitizes breast cancer MCF7 cells to cisplatin and pentoxifylline. Cancer Res 1995; 55:1649-54

Friedberg EC, Bardwell AJ, Bardwell L, Feaver WJ, Kornberg RD, Svejstrup JQ, Tomkinson AE, Wang Z. Nucleotide excision repair in the yeast Saccharomyces cerevisiae: its relationship to specialized mitotic recombination and RNA polymerase II basal transcription. Philos Trans R Soc Lond B Biol Sci 1995;347:63-8

Gaiddon C, Moorthy NC, Prives C. Ref-1 regulates the transactivation and pro-apoptotic functions of p53 in vivo. EMBO J 1999;185:5609-21

Giaccia AJ, Kastan MB. The complexity of p53 modulation: emerging patterns from divergent signals. Genes Dev 1998; 12:2973-83

Gostissa M, Hengstermann A, Fogal V, Sandy P, Schwarz 
SE, Scheffner M, Del Sal G. Activation of p53 by conjugation to the ubiquitin-like protein SUMO-1. EMBO J 1999;18:646271

Gu W, Roeder RG. Activation of p53 sequence-specific DNA binding by acetylation of the C-terminal domain. Cell 1997; 90:595-606

Hawkins DS, Demers GW, Galloway DA. Inactivation of p53 enhances sensitivity to multiple chemotherapeutic agents. Cancer Res 1996;56:892-8

Hollander MC, Kovalsky O, Salvador JM, Kim KE, Patterson $A D$, Haines DC, Fornace AJ Jr. Dimethylbenzanthracene carcinogenesis in Gadd45a-null mice is associated with decreased DNA repair and increased mutation frequency. Cancer Res 2001;61:2487-91

Hwang BJ, Ford JM, Hanawalt PC, Chu G. Expression of the p48 xeroderma pigmentosum gene is p53-dependent and is involved in global genomic repair. Proc Natl Acad Sci USA 1999;96:424-8

Itoh T, Linn S, Ono T, Yamaizumi M. Reinvestigation of the classification of five cell strains of xeroderma pigmentosum group $E$ with reclassification of three of them. J Invest Dermatol 2000;114:1022-9

Jayaraman L, Murthy KG, Zhu C, Curran T, Xanthoudakis $S$, Prives C. Identification of redox/repair protein Ref-1 as a potent activator of p53. Genes Dev 1997;11:558-70

Jin S, Tong T, Fan W, Fan F, Antionore MJ, Zhu X, Mazzacurati L, Li X, Petrik KL, Rajasekaran B, Wu M, Zhan Q. Gadd45-induced cell cycle G2-M arrest associates with altered subcellular distribution of cyclin B1 and is independent of p38 kinase activity. Oncogene 2002;21:8696-704

Knudson CM, Tung KS, Tourtellotte WG, Brown GA, Korsmeyer SJ. Bax-deficient mice with lymphoid hyperplasia and male germ cell death. Science 1995;270:96-9

Ko LJ, Prives C. p53: puzzle and paradigm. Genes Dev 1996;10:1054-72

Lackinger D, Kaina B. Primary mouse fibroblasts deficient for p53 are hypersensitive to UV light and alkylating agentinduced chromosomal breakage and apoptosis. Mutat Res 2001;457:113-23

Lee JE, Sohn J, Lee JH, Lee KC, Son CS, Tockgo YC. Regulation of bcl-2 family in hydrogen peroxide-induced apoptosis in human HL-60 cells. Exp Mol Med 2000;32:42-6

Lee YS, Chung MH. Base excision repair synthesis of DNA containing 8-oxoguanine in Escherichia coli. Exp Mol Med 2003;35:106-12

Leveillard T, Andera L, Bissonnette N, Schaffer L, Bracco L, Egly JM, Wasylyk B. Functional interactions between p53 and the TFIIH complex are affected by tumour-associated mutations. EMBO J 1996;15:1615-24
Matsumoto Y, Kim K, Hurwitz J, Gary R, Levin DS, Tom kinson $A E$, Park MS. Reconstitution of proliferating cell nuclear antigen-dependent repair of apurinic/apyrimidinic sites with purified human proteins. J Biol Chem 1999;274: 33703-8

Meek DW. Mechanisms of switching on p53, A role for covalent modifications. Oncogene 1999;18:7666-75

Offer H, Zurer I, Banfalvi G, Reha'k M, Falcovitz A, Milyausky M, Goldfinger N, Rotter V. p53 modulates base excision repair activity in cell cycle specific manner after genotoxic stress. Cancer Res 2001;61:88-96

Pluquet $\mathrm{O}$, Hainaut P. Genotoxic and non-genotoxic pathways of p53 induction. Cancer Lett 2001;174:1-15

Prives C, Hall PA. The p53 pathway. J Pathol 1999;187: $112-26$

Rodriguez MS, Desterro JM, Lain S, Midgley CA, Lane DP, Hay RT. SUMO-1 modification activates the transcriptional response of p53. EMBO J 1999;18:6455-61

Ryan KM, Phillips AC, Vousden KH. Regulation and function of the p53 tumor suppressor protein. Curr Opin Cell Biol 2001;13:332-7

Seo YR, Chen El, Smith ML. Sensitivity of p53-deficient cells to oxaliplatin and thio-TEPA (N, N', N" triethylenethiophosphoramide). Breast Cancer Res Treat 2002a;72: 255-63

Seo YR, Foster LM, Kelley ML, Smith ML. Implication for p53 in Base Excision Repair: In vivo Evidence. Oncogene 2002b;21:731-7

Seo YR, Kelley ML, Smith ML. Selenomethionine regulation of $p 53$ by a ref1-dependent redox mechanism. Proc Natl Acad Sci USA 2002c;99:14548-53

Smith ML, Ford JM, Hollander MC, Bortnick RA, Amundson SA, Seo YR, Deng C, Hanawalt PC, Fornace AJ Jr. P53mediated DNA repair responses to UV-radiation: Studies of mouse cells lacking p53, p21, and/or gadd45 genes. Mol Cell Biol 2000;20:3705-14

Stucki M, Pascucci B, Parlanti E, Fortini P, Wilson SH, Hubscher U, Dogliotti E. Mammalian base excision repair by DNA polymerase delta and epsilon. Oncogene 1998;7:835-43

Tokino T, Thiagalingam S, el-Deiry WS, Waldman T, Kinzler $\mathrm{KW}$, Vogelstein B. p53 tagged sites from human genomic DNA.. Hum Mol Genet 1994;3:1537-42

Ueno M, Masutani H, Arai RJ, Yamauchi A, Hirota K, Sakai T, Inamoto T, Yamaoka Y, Yodoi J, Nikaido T. Thioredoxindependent redox regulation of p53-mediated p21 activation. J Biol Chem 1999;274:35809-15

Wilson SH, Kunkel TA. Passing the baton in base excision repair. Nat Struct Biol 2000;7:176-8

Zhou J, Ahn J, Wilson SH, Prives C. A role for p53 in base excision repair. EMBO J 2001;20:914-23 